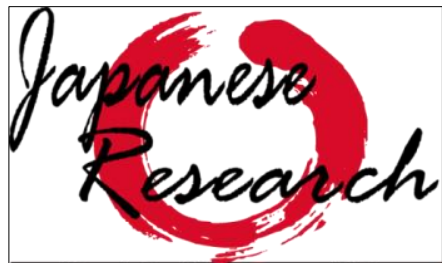

on Linguistics, Literature and Culture
Japanese Research on Linguistics, Literature, and Culture

Vol. 2 No. 2 May 2020, Hal. 108-125 ISSN online: 2655-4836

Doi: 10.33633/jr.v2i2.3993

http://publikasi.dinus.ac.id/index.php/jrllc/article/view/3993/2025

japanese.research@fib.dinus.ac.id

Published by Universitas Dian Nuswantoro, Semarang

\title{
Analisis Sosiolinguistik Politeness Bahasa Jepang dalam Film Galileo 2013 Karya Keigo Higashino
}

\author{
Yuniati Fadhillah \\ Universitas Dian Nuswantoro \\ 312201600671@mhs.dinus.ac.id
}

Article History: Submitted date 2020-08-24; Accepted date 2020-08-29; Published date 2020-08-31

\begin{abstract}
This research discusses the various languages of respect (keigo), namely sonkeigo, kenjougo, and teineigo. This study aims to examine the use of keigo language and the factors that influence the use of keigo, especially in the work environment. The theory used in this study is based on Sachiko's sociolinguistic theory of distance. The data used is a Japanese film entitled Galileo 2013 by Keigo Higashino. The research method of this study show uses descriptive qualitative method. The results of this study show that the use of respectful language keigo (kenjougo and teineigo) is used between participants in the scope of uchi mono. Whereas the use of the various keigo languages (sonkeigo) is used by speakers of speech partners in the scope of soto mono, formal or informal situations, age or higher position. Factors that influence the use of keigo according to Sachiko's Idea theory are the factors that take into consideration of the use of keigo in the uchi mono group is social distance, because the speaker speaks to the speech partner, based on position or age position. Whereas the dominant factor that becomes a consideration for the use of keigo in the soto mono group is social distance and formality distance, because the speech partners who speak with many speakers do not use a variety of respectful languages (keigo), because the speech partners feel they are older than the speakers, and consider not formal talks because it's not from his job.
\end{abstract}

Keywords: Keigo, social factors, distance, uchi mono, soto mono

\begin{abstract}
Abstrak
Peneliti membahas ragam bahasa hormat (keigo), yaitu sonkeigo, kenjougo, dan teineigo. Penelitian ini bertujuan untuk mengkaji penggunaan bahasa keigo dan faktor-faktor yang mempengaruhi penggunaan keigo khususnya di lingkungan kerja. Teori yang digunakan dalam penelitian ini berdasarkan teori sosiolinguitik Ide Sachiko tentang jarak. Data yang digunakan adalah sebuah film Jepang yang berjudul Galileo 2013 karya Keigo Higashino.
\end{abstract}


Metode penelitian ini menggunakan metode deskriptif kualitatif. Hasil penelitian ini disimpulkan bahwa penggunaan bahasa hormat keigo (kenjougo dan teineigo) yang digunakan antarpartisipan dalam lingkup uchi mono. Sedangkan penggunaan ragam bahasa keigo (sonkeigo) digunakan penutur kepada mitra tutur dalam lingkup soto mono, situasi formal maupun tidak formal, usia atau kedudukan yang lebih tinggi. Faktor yang mempengaruhi penggunaan keigo menurut teori Ide Sachiko yaitu faktor yang menjadi pertimbangan penggunaan keigo dalam kelompok uchi mono adalah jarak sosial, karena penutur berbicara kepada mitra tutur, berdasarkan posisi kedudukan atau usia. Sedangkan faktor dominan yang menjadi pertimbangan penggunaan keigo dalam kelompok soto mono adalah jarak sosial dan jarak formalitas, karena mitra tutur yang berbicara dengan penutur banyak yang tidak menggunakan ragam bahasa hormat (keigo), karena mitra tutur merasa usianya lebih tua dari penutur, dan menganggap tidak formal pembicaraannya karena bukan dari pekerjaannya.

Kata kunci : Keigo, faktor sosial, jarak, uchi mono, soto mono

\section{Pendahuluan}

Ragam bahasa digunakan untuk menyatakan rasa hormat kepada mitra tutur atau seseorang yang sedang dibicarakan disebut keigo. Bahasa Jepang dikenal tidak hanya penulisan huruf yang terlihat sulit, tetapi karena faktor sosial budaya masyarakat Jepang yang berkaitan dengan kesopanan dan keformalan. Kesopanan berkaitan dengan formalitas (formality) dan penghormatan (respect). Keigo secara umum digunakan saat berkomunikasi dengan seseorang yang lebih tinggi dari posisi sosialnya (segi usia maupun tingkat kedudukan). Selain bermaksud menghormati, keigo juga digunakan sebagai ragam merendahkan diri, yaitu dengan menggunakan bahasa merendah untuk aktifitas yang dilakukan. Maksud merendahkan diri tersebut bukan berarti membuat seseorang rendah dihadapan mitra tutur, justru mitra tutur akan memandang orang tersebut sebagai orang yang sopan dan beretika. Ragam bahasa hormat biasanya sering digunakan orang yang sudah bekerja, atau orang dewasa yang sudah mengabdikan diri di lingkungan masyarakat. Jadi, di lingkungan orang dewasa biasanya sering diperlukan penggunaan keigo, seperti saat di tempat kerja penggunaan keigo ditentukan berdasarkan tingkatan, jabatan, atau posisi sosial di masyarakat. Oleh karena itu, penggunaan keigo di masyarakat Jepang lebih dominan digunakan di lingkungan kerja. Sedangkan anak yang masih kecil atau siswa di sekolah tidak menggunakan ragam bahasa sonkeigo atau kenjougo dalam kegiatan setiap hari. 
Penggunaan keigo dalam percakapan bahasa Jepang termasuk tinggi frekwensinya karena berhubungan dengan peran sosial partiipannya. Hal ini menjadi penting untuk dikaji karena keberadaannya menentukan harmoni dalam masyarakat. Kesalahan dalam penggunaan keigo dapat berpotensi merusak hubungan sosial. Penggunaan keigo dapat dilihat dalam contoh berikut:

(a)もう新聞を読みましたか?

Mou shinbun wo yomi + mashita $+k a$ ?

Sudah surat kabar OM $\underline{\text { membaca }}+\mathrm{T}+\mathrm{Pst}+\mathrm{Q}$

(b) もう新聞をお読みになりましたか?

Mou shinbun wo $\underline{o}+$ yomi $+\underline{\text { ni nari }}+\underline{\text { mashita }}+k a$ ?

Sudah surat kabar OM membaca + Son $+T+$ past $+Q$

Pada kalimat di atas, merupakan kalimat yang sama artinya, yaitu menanyakan apakah mitra tutur sudah membaca surat kabar atau belum. Pelaku (subjek) dalam kalimat tersebut adalah mitra tutur.

Pada kalimat (a) menggunakan verba 読みましたか merupakan kalimat teineigo. Penggunaan bahasa teineigo tersebut untuk mengatakan isi pembicaraan secara halus atau sopan kepada mitra tutur, tidak meninggikan mitra tutur ataupun merendahkan penutur. Biasanya digunakan penutur kepada mitra tutur yang memiliki usia atau tingkat kedudukan yang sama. Sedangkan pada kalimat (b) mengandung verba お読みになりましたか merupakan kalimat sonkeigo. Verba お読みになりました dibentuk dari 読みました, yaitu bentuk masu yang ditambahkan お dan になる. Penggunaan bahasa hormat sonkeigo tersebut sebagai penanda bahwa status penutur lebih rendah dibandingkan subjek yang menjadi topik pembicaraan. Bahasa hormat ini digunakan saat berkomunikasi dengan seseorang yang usianya lebih tua dari penutur atau seseorang yang kedudukanya lebih tinggi. Misalnya buchou berbicara kepada sachou. Orang Jepang menggunakaan tingkatan ini sebagai bentuk bahasa meninggikan mitra tutur.

Bagi pemelajar yang belum pernah menggunakan ragam bahasa hormat seperti di atas, akan merasa kesulitan dalam memahami maksud dari ungkapan-ungkapan seperti kalimat di atas. Oleh karena itu penulis tertarik untuk menganalisis penggunaan keigo, karena akan 
bermanfaat oleh pemelajar bahasa Jepang agar dengan mudah mengetahui penggunaan keigo saat berkomunikasi di lingkungan masyarakat terutama di lingkungan tempat kerja. Pemelajar bahasa Jepang akan mengetahui bahwa ragam bahasa sopan tidak hanya menggunakan akhiran

「ます」(masu) dan「です」(desu) saja, tetapi juga dapat mengetahui dan menggunakan ragam hormat keigo dengan benar.

\section{Kajian Teoretis}

Peneliti menggunakan teori kesantunan oleh Ide dan teori pembagian keigo dalam bahasa Jepang yang berlaku secara umum. Menurut Ide (1982 dalam Saifudin, 2005:18),, pilihan penggunaan bahasa yang berkaitan dengan kesopanan melibatkan dua jenis aturan, yaitu aturan linguistik dan aturan sosial. Aturan linguistik berarti berhubungan dengan bentuk tata bahasa, dan dalam bahasa Jepang terdapat sistem yang mengatur penggunaan tingkat kesopanan berbahasa, yakni sistem keigo "bahasa hormat". Aturan sosial berarti perilaku yang patut sesuai nilai atau norma yang berlaku pada masyarakat. Menurut Ide, faktor yang terutama adalah tergantung pada situasi yang lebih banyak ditentukan oleh faktor jarak (distance) yang dirasakan oleh penutur maupun mitra tutur. Jarak yang dimaksud adalah jarak status sosial (perbedaan status, usia, pangkat), jarak formalitas (formalitas peristiwa, latar pengetahuan antarpartisipan, topik), dan jarak psikologis (penghormatan, kedekatan, penjauhan).

\section{Metode Penelitian}

Pada penelitian ini penulis menggunakan metode penelitian deskriptif kualitatif dengan ancangan sosiolinguistik. Data yang digunakan penelitian ini adalah ragam bahasa hormat (keigo) yang terdapat pada film. Film Galileo 2013 merupakan drama Jepang yang dibuat dari cerita novel Detektif Galileo (探偵ガリレオ Tantei Garireo) oleh penulis pencinta cerita misteri yang terkenal yaitu Keigo Higashino (東野 圭吾 Higashino Keigo). Langkah-langkah yang dilakukan peneliti dalam menganalisis data, yaitu mendeskripsi atau menjelaskan situasi yang terjadi pada percakapan. Mengidentifikasi penggunaan ragam bahasa hormat (keigo) dalam film Galileo 2013. Menjabarkan para partisipan yang terlibat dalam percakapan. Mengklasifikasi hubungan antarpartisipan, yaitu dalam lingkup uchi mono atau soto mono, kemudian diklasifikasikan lagi berdasarkan percakapan antara status rendah dan tinggi, status sama, atau status rendah dan tinggi. Mendeskripsikan atau menjelaskan jenis ragam bahasa hormat (keigo), yaitu sonkeigo, 
kenjougo, atau teneigo dalam percakapan. Menganalisis faktor-faktor yang menjadi pertimbangan dalam penggunaan ragam bahasa hormat (keigo) berdasarkan teori sosiolinguistik Ide Sachiko. Terakhir, menentukan faktor "jarak" yang lebih dominan menjadi pertimbangan penggunaan keigo dalam kelompok uchi mono atau soto mono.

\section{Hasil dan Pembahasan}

\section{Penggunaan Keigo Pada Lingkup Uchi Mono}

\section{Penggunaan keigo pada status rendah dan tinggi}

Data 1

a. Percakapan

お田川さん：ばあさんが亡くなるまで散歩してたってか?こりや殺しの可能性もあ りますね。

Otagawa-san : Baasan ga nakunaru made sanpo shite tatte ka? Korya koroshi no kanousei mo arimasu ne. (Apakah ia membawanya jalan-jalan sampai dia meninggal? Ini mungkin kasus pembunuhan)

雅紀さん：すぐに調べに入ってくれ。

Masaki-san : Sugu ni shirabe ni haitte kure. (Ayo segera mulai selidiki kasus ini!)

お田川さん：はい！

Otagawa-san : Hai ! (Ya, siap!)

内海さん：待って下さい、私にやらせてもらえませんか? お願いします、職質した のは私です。(1.1)

Utsumi-san : Matte kudasai, watashi ni yarasete moraemasenka? Onegaishimasu, shoku shitsu shita no wa watashi desu. (Tunggu sebentar, izinkanlah saya untuk melakukannya? Saya Mohon, sayalah yang awalnya menanyainya)

雅紀さん：おう。

Masaki-san :Ou (Baiklah)

内海さん：ありがとうございます。

Utsumi-san : Arigatou gozaimasu. (Terimakasih)

(Galileo 2013, 00:07:03) 
b. Partisipan percakapan

- Mamiya Masaki-san : Kepala kepolisian (shochou)

- Otagawa-san : Detektif (senpai)

- Utsumi-san : Detektif muda (kouhai)

c. Analisis data

Penggunaan keigo yang terdapat pada percakapan data 2 adalah keigo yang digunakan meshita kepada meue dalam lingkup uchi mono dengan jenis keigo kenjougo dan teineigo.

Percakapan data 1 situasi terjadi saat seluruh karyawan kepolisian mengadakan rapat membahas penyebab kematian seorang wanita tua bernama Iwami Fumi-san, salah satu tim penyelidik berargumen bahwa Fumi-san mengalami penyakit "Dementia" atau lumpuh. Diperkirakan bahwa Fumi-san meninggal saat tiba di Tokyo dan dibawa jalan-jalan oleh perawatnya sendiri yang bernama Jounen-san. Salah satu detektif yaitu Otogawa-san berpikir bahwa kematian Fumi-san merupakan kasus pembunuhan, oleh karena itu semua karyawan kepolisian diperintah oleh Kepala Masaki-san untuk menyelidiki perawat tersebut. (1.1) Utsumisan bergegas berbicara agar Kepala Masaki-san dan rekan kerja lainnya tidak membubarkan rapat, dia berbicara dengan merendahkan diri menggunakan ragam hormat kenjougo pada kalimat 待って下さい yang berarti “tunggu sebentar!”. Kemudian Utsumi-san mengajukan diri kepada Kepala Mamiya Masaki-san agar dia diizinkan ikut serta dalam penyelidikan tersebut. Penggunaan ragam bahasa yang digunakan Utsumi-san saat meminta izin ikut serta penyelidikan adalah ragam sopan teineigo, yaitu pada pola kalimat やらせてもらえませんか?. Kedua, ragam bahasa sopan teineigo karena percakapan di atas dalam situasi formal. Kata yang termasuk teineigo yang dipakai oleh Utsumi-san saat mengatakan「お願いします」adalah verba bantu [ます]. [ます] “masu” merupakan kopula yang tidak memiliki arti namun sangat besar pengaruhnya dalam percakapan sehari-hari dan menandakan kesopanan (teineigo).

d. Percakapan data 1 dapat diidentifikasi secara linguistik bahwa keigo yang digunakan adalah : 
- [〜ください] : bermakna permintaan atau seseorang melakukan sesuatu secara sopan (kenjougo),

- [やらせる] ： bermakna leksikal "biarkan saya lakukan”,

- [〜てもらえませんか] : bentuk lebih sopan dari te moraemasuka dan merupakan bentuk negatifnya, masu dihilangkan lalu di tempel masen dan ditambah $\sim k a$ sebagai penanda kalimat tanya (teineigo)

- [〜ます] : bermakna gramatikal berfungsi sebagai penanda bentuk sopan (teineigo)

e. Berdasarkan teori Ide tentang jarak, maka analisisnya adalah sebagai berikut :

- Jarak sosial

Apabila dilihat dari jarak status sosialnya Mamiya Masaki-san memiliki kekuasaan (power) atau posisi sosial yang lebih tinggi, karena statusnya sebagai Kepala Polisi, kemudian Otagawasan dan rekan kerja lainnya merupakan senpai atau senior di tempat kerja, serta lebih tua usianya dari Utsumi-san, sedangkan Utsumi-san detektif wanita pemula dan lebih muda usianya.

- Jarak formalitas

Apabila dilihat dari formalitas peristiwa, merupakan peristiwa yang formal karena percakapan terjadi saat diadakan sebuah rapat, yang dihadiri oleh Kepala Kepolisian dan para detektif yang membahas tentang penyebab kematian seorang wanita tua bernama Iwami Fumisan. Hubungan sosial antarpartisipan adalah hubungan profesional atau hubungan sebatas pekerjaan. Meskipun peristiwanya formal karena terjadi saat rapat berlangsung, tetapi Masakisan tidak menganggapnya formal, ini dibuktikan dengan ragam non keigo yang digunakan, sementara Utsumi-san menganggapnya formal.

- Jarak psikologis

Jarak psikologis tercipta berdasarkan pada rasa hormat, dan kejauhan atau kedekatan. Apabila dilihat dari rasa hormat, Utsumi-san mengungkapkan rasa hormat kepada mitra tutur dengan mempertimbangkan kedudukan mitra tutur yang lebih tinggi yaitu kepada Masaki-san sebagai meue atau atasannya, dan Otagawa-san sebagai senpai. Apabila dilihat dari kedekatan 
antarpartisipan, Utsumi-san dan Masaki-san termasuk hubungan dalam satu tempat pekerjaan sehingga masuk dalam kelompok uchi mono.

Faktor penggunaan keigo tersebut dilatarbelakangi oleh beberapa hal yaitu faktor jarak sosial, jarak formalitas, dan jarak psikologis. Berdasarkan jarak sosial yang menjadi pertimbangannya adalah faktor hubungan sosial dan faktor tingkat kedudukan dalam lingkungan kerja. Status Utsumi-san yang secara sosial lebih rendah dibandingkan dengan mitra tutur yang merupakan meue dan lebih tua usianya. Jarak formalitas karena percakapan terjadi di ruang rapat. Jarak psikologis berupa rasa hormat serta kedekatan psikologis di antara keduanya (uchi mono).

Jadi dalam hal ini faktor dominan yang menjadi pertimbangan penggunaan keigo adalah jarak sosial dibandingkan dengan jarak fomalitas dan psikologis, ini terbukti dengan penggunaan non keigo oleh Masaki-san meskipun dalam situasi formal, sementara secara psikologis seharusnya ketika jaraknya dekat cenderung akan menggunakan ragam bahasa akrab.

\subsection{Penggunaan keigo pada status tinggi dan rendah}

\section{Data 2}

a. Percakapan

内海さん：あの私はまだ何も

Utsumi-san : Ano watashi wa mada nani mo (Maaf, apa yang harus kulakukan?)

多々良さん：じやあ、送致の資料でもまとめといてもらえますか? (2.1)

Tatara-san : Jaa, okusuu no shiryou demo matome to ite moraemasuka? (Kalau begitu, bisakah kau rapikan dokumen-dokumen?)

内海さん：捜査に参加させてほしいです。(2.2)

Ustumi-san : Souse ni sankasasete hoshii desu. (Aku ingin berparti sipasi dalam penyelidikan)

(Galileo 2013, 00:20:00)

b. Pastisipan percakapan

- Tatara-san : Wakil Kepala Departemen Kepolisian Metropolitan (meue)

- Utsumi-san : Detektif pemula (meshita) 
c. Analisis

Penggunaan keigo yang terdapat pada percakapan di atas adalah keigo yang digunakan meue kepada meshita dalam lingkup uchi mono dengan jenis keigo teineigo.

Percakapan data 2 terjadi ketika saat di kantor Wakil Ketua Tatara-san membagikan tugas kepada bawahannya, kecuali kepada Ustumi-san. Lalu Utsumi-san meminta tugas dari Wakil Ketua, namun Utsumi-san menolak perintah yang hanya merapikan dokumen-dokumen di kantor, karena ia juga ingin berpartisipasi langsung ke TKP dalam penyelidikan kasus pembunuhan tersebut. Berdasarkan percakapan (2.1) Tatara-san memerintah Utsumi-san selaku bawahanya menggunakan ragam bahasa teineigo. Bentuk teineigo ditandai pada bentuk pola $\sim$ てもらえますか. Kemudian (2.2) Utsumi-san meminta izin persetujuan kepada Tatara-san agar dapat berpartisipasi penyelidikan menggunakan ragam bahasa merendahkan diri juga dengan ragam bahasa sopan teineigo menggunakan pola kalimat 参加させてほしいです.

d. Analisis Sosiolinguistik

Percakapan data 7 dapat diidentifikasi secara linguistik bahwa keigo yang digunakan adalah :

- [〜てもらえますか] : bentuk sopan, bermakna mengajukan "permintaan" kepada mitra tutur (teineigo),

- Verba [参加させてほしいです] (teineigo),

Penjelasannya :

[参加させて] ： bermakna leksikal “berpartisipasi atau ikut serta”

[ほしい] : : bermakna leksikal “keinginan”

[〜です] : : bermakna gramatikal berfungsi sebagai penanda sopan (teineigo)

e. Berdasarkan teori Ide tentang jarak, maka analisisnya adalah sebagai berikut :

- Jarak sosial 
Apabila dilihat dari jarak status sosialnya Tatara-san mempunyai kedudukan atau posisi sosial yang lebih tinggi daripada Utsumi-san karena statusnya sebagai Wakil Kepala Departemen Kepolisian Metropolitan, sedangkan Utsumi-san sebagai detektif muda (meshita).

- Jarak formalitas

Apabila dilihat dari formalitas peristiwa, merupakan dalam peristiwa formal.Percakapan terjadi di ruang kantor Wakil Kepala Tatara-san pada waktu kerja, topik pembicaraannya yaitu Tatara-san membagikan tugas kepada bawahannya untuk pergi menyelidiki TKP atau tempat pembunuhan itu terjadi, kecuali Ustumi-san yang hanya ditugaskan merapikan dokumen di kantornya, dan akhirnya Utsumi-san meminta untuk berpartisipasi dalam penyelidikan tersebut. - Jarak psikologis

Jarak psikologis tercipta berdasarkan pada rasa hormat, dan kejauhan atau kedekatan. Apabila dilihat dari rasa hormat dari Utsumi-san kepada mitra tutur karena mitra tutur adalah meue atau atasan di tempat kerja. Apabila dilihat dari kedekatan antarpartisipan, Utsumi-san dan Tatara-san termasuk hubungan dalam satu tempat pekerjaan sehingga masuk dalam kelompok uchi mono.

Faktor penggunaan keigo tersebut dilatarbelakangi oleh beberapa hal yaitu faktor jarak sosial, jarak formalitas, dan jarak psikologis. Berdasarkan jarak sosial yang menjadi pertimbangannya adalah faktor hubungan sosial dan faktor tingkat kedudukan dalam lingkungan kerja. Utsumi-san menggunakan keigo berdasarkan pada faktor jarak sosial karena mitra tutur merupakan seorang atasan dan lebih tua usianya. Jarak formalitas karena percakapan terjadi di ruang kantor dan pada waktu kerja. Jarak psikologis berupa rasa hormat serta kedekatan psikologis di antara keduanya.

Jadi dalam hal ini faktor dominan yang menjadi pertimbangan penggunaan keigo adalah jarak sosial dibandingkan dengan jarak fomalitas dan psikologis, ini terbukti dengan percakpan awal Utsumi-san menggunakan non keigo meskipun dalam situasi formal, setelah Tatara-san merespon Utsumi-san dengan keigo maka Utsumi-san pun mengubah bahasa bicaranya menggunakan ragam bahasa keigo. Sedangkan secara psikologis seharusnya ketika jarak hubungannya dekat Tatara-san seharusnya akan menggunakan ragam bahasa akrab atau futsuu. 


\section{Penggunaan Keigo Pada Lingkup Soto Mono.}

\section{Penggunaan keigo pada status rendah dan tinggi}

Data 3

a. Percakapan

堀口さん：お待たせしました。これ上念さんの介護日誌。(3.1)

Horiguchi-san : Omatase shimashita. Kore Jounen-san no kaigo nisshi. (Maaf membuatmu terus menunggu. Ini diary Jounen-san)

\section{内海さん： ありがとうございました。(3.2)}

Utsumi-san : Arigatou gozaimashita. (Terimakasih banyak)

(3.3) 堀口さん：きちょうめんでしょう?きっちりしたひとだったから。色々と重宝 したのよ。あの人パソコンも詳しいからうちのホームページも作っ てくれてたし。

Horiguchi-san : Kichoumendeshou? Kicchiri shita hito datta kara. Iro-iro to chouhou shita no yo. Ano hito pasokon mo kuwashii kara uchi no houmupeeji mo tsukutte kuretetashi. (Dia sangat teliti. Dia juga sangat ringan tangan. Karena tahu banyak tentang komputer dia membuat sebuah website untuk kami)

(Galileo 2013, 00:27:11)

b. Partisipan percakapan

- Utsumi-san : Detektif muda

- Horiguchi-san : Ketua perawat (atasan Jounen-san)

c. Analisis

Penggunaan keigo yang terdapat pada percakapan di atas adalah keigo yang digunakan Horiguchi-san dalam lingkup soto mono dengan jenis keigo sonkeigo.

Percakapan data 3 terjadi saat Utsumi-san dan Kento-san mengunjungi rumah Jounensan. Utsumi-san meminta seorang perawat atau rekan kerja Jounen untuk datang membawa buku catatan milik Jounen yang ingin mereka selidiki. Setelah beberapa lama akhirnya perawat tersebut datang ke rumah Jounen-san dengan membawa buku catatan yang diminta Utsumi-san 
tersebut. Berdasarkan percakapan (3.1) Horiguchi-san membuat mitra tuturnya menunggu, karena dia harus mencari buku catatan atau diary milik Jounen-san. Horiguchi-san berbicara dengan rasa hormat kepada Utsumi-san menggunakan ragam bahasa sonkeigo, ditandai dengan munculnya kata [お待たせしました] “omataseshimashita”. Alasan digunakannya bentuk tersebut karena kata itu merupakan salah satu penanda sonkeigo yaitu dengan menyisipkan verba bentuk renyoukei pada pola “o-suru”. Kata [お待たせしました] “omataseshimashita” berasal dari bentuk biasa atau joutai [まっている] "matte iru" yang artinya "menunggu". Kemudian (3.2) Utsumi-san menjawab menggunakan ragam bahasa sopan teineigo pada bentuk kalimat ありがとうございました yang berarti “terimakasih banyak”.

d. Analisis Sosiolinguistik

Percakapan data 3 dapat diidentifikasi secara linguistik bahwa keigo yang digunakan adalah :

- Verba [お待たせしました] (sonkeigo + teineigo)，

Penjelasannya :

[お〜する] : sonkeigo (verba bentuk renyoukei pada pola o-suru)

[まっている] : "matte iru” yang artinya "menunggu"

- Verba [ありがとうございました] (teineigo),

Penjelasannya :

[ありがたい]+[〜おうござる]+[ます $]+[$ た $]$

[ありがたい] ： bermakna leksikal "terima kasih”

[〜おうござる] ： bermakna gramatikal pembentuk kenjougo

[〜ござる] ： bermakna leksikal “menunjukkan suatu keadaan atau hal”. Pemakaian kata (gozaru) selalu dalam bentuk sopan (gozaimasu)

[〜ます]+[た] : bermakna gramatikal berfungsi sebagai penanda bentuk sopan, perbuatan lampau atau sudah selesai (teineigo)

- [〜でしょう] : penanda sopan (teineigo) dugaan 
e. Berdasarkan teori Ide tentang jarak, maka analisisnya adalah sebagai berikut : Jarak sosial

Apabila dilihat dari jarak sosial antarpartisipan memiliki perbedaan status. Utsumi-san dan Kento-san berstatus sebagai detektif, sedangkan Horiguchi-san berstatus ketua perawat (atasan Jounen-san).

- Jarak formalitas

Apabila dilihat dari formalitas peristiwa, merupakan dalam peristiwa formal. Percakapan terjadi saat Utsumi-san dan Kento-san di rumah Jounen-san untuk menyelidiki apakah ada yang bisa dijadikan barang bukti atau faktor penyebab Jounen-san melakukan pembunuhan terhadap majikannya. Oleh karena itu Utsumi-san meminta rekan kerja Jounen-san untuk dibawakan buku atau catatan diary atau jadwal pekerjaan Jounen-san.

- Jarak psikologis

Jarak psikologis tercipta berdasarkan pada rasa hormat, dan kejauhan atau kedekatan. Apabila dilihat dari rasa hormat, Utsumi-san menunjukkan hormat terhadap mitra tutur, karena Utsumi berbicara dengan seseorang yang lebih tua usianya. Apabila dilihat dari kejauhan antara Utsumi-san dan mitra tutur, keberadaan antarpartisipan berada pada kelompok yang berbeda atau beda profesi dan hubungan antarpartisipan yang belum akrab.

Faktor penggunaan keigo tersebut dilatarbelakangi oleh beberapa hal yaitu faktor jarak sosial, jarak formalitas, dan jarak psikologis. Berdasarkan jarak sosial yang menjadi pertimbangannya adalah faktor hubungan yaitu antara detektif dengan perawat atau beda profesi. Jarak formalitas hubungan antarpartisipan adalah tidak saling kenal atau tidak ada hubungan keluarga maupun pekerjaan. Jarak psikologis Utsumi-san merendahkan perilakunya sendiri terhadap mitra tutur, karena Utsumi berbicara dengan seseorang yang belum akrab atau seseorang yang baru ditemui.

Jadi dalam hal ini faktor dominan yang menjadi pertimbangan penggunaan keigo adalah jarak psikologis, karena penutur dan mitra tutur baru saja bertemu sehingga jarak psikologis antarpartisian adalah kejauhan dan termasuk dalam kelompok soto mono.

\section{Data 4}


a. Percakapan

(4.1) 瀧山さん： ちょっと失礼。上念さんの弁護士をしている瀧山と申しますが、こ れは正式な捜査ですか?

Takiyama-san : Chotto sitsurei. Jounen-san no bengoshi o shite iru Takiyama tomoushimasu ga, kore wa seishikina sousa desuka? (Maaf menganggu, saya Takiyama pengacaranya Jounen, apakah ini penyelidikan resmi?)

(4.2)内海さん：いいえ、事件は真犯人が捕まって終了しました。

Utsumi-san : lie, jiken wa shinhannin ga tsukamatte shuuryou shimashita.(Bukan, karena pelaku sebenarnya telah ditangkap, penyelidikan terhadap insiden itu sudah selesai)

(Galileo 2013, 01:27:12)

b. Partisipan percakapan

- Takiyama-san : Pengacara Jounen-san

- Utsumi-san : Detektif muda

c. Analisis data

Penggunaan keigo yang terdapat pada percakapan di atas adalah keigo yang digunakan oleh Takiyama-san dalam lingkup soto mono dengan jenis keigo kenjougo dan teineigo.

Percakapan data 4 ketika Utsumi-san masuk ke ruangan Jounen-san, kemudian Takiyamasan selaku pengacara Jounen-san yang melihat Utsumi-san dan mengetahui bahwa dia adalah detektif. Maka Takiyama-san bermaksud memperkenalkan diri serta menanyakan apakah dia akan melakukan penyelidikan kembali dengan Jounen-san atau tidak. Berdasarkan percakapan (4.1) bisa diketahui bahwa hubungan antara Takiyama-san dan Utsumi-san tidak akrab, karena mereka baru pertama kali bertemu. Sehingga Takiyama-san menggunakan ragam bahasa kenjougo pada saat ia ingin memperkenalkan diri kepada Utsumi-san. Bentuk kenjougo digunakan untuk merendahkan diri sendiri dan menunjukkan rasa hormat terhadap mitra tutur. Hal ini ditandai dengan munculnya kata moushimasu [申します]. Penggunaan teineigo ditandai 
dengan menggunakan kopula [〜です]. Sedangkan Utsumi-san (4.2) merespon dengan menggunakan ragam bahasa halus atau sopan teineigo pada bentuk [ 〜ました].

d. Percakapan data 4 dapat diidentifikasi secara linguistik bahwa keigo yang digunakan adalah :

- Verba [申します] : perkenalan bentuk sopan (kenjougo),

- [〜です] : bermakna gramatikal berfungsi sebagai penanda bentuk sopan (teineigo)

- [〜ます]+[た] : bermakna gramatikal berfungsi sebagai penanda bentuk sopan, perbuatan lampau atau sudah selesai (teineigo)

e. Berdasarkan teori Ide tentang jarak, maka analisisnya adalah sebagai berikut :

- Jarak sosial

Apabila dilihat dari jarak ataupun status sosial pada percakapan diatas merupakan beda status pekerjaan. Utsumi-san seorang detektif, sedangkan Takiyama-san seorang pengacara Jounen-san, hubungan mereka tidak saling akrab karena baru pertama kalinya bertemu.

- Jarak formalitas

Apabila dilihat dari formalitas peristiwa, merupakan dalam peristiwa formal.

Percakapan terjadi saat berada di pameran buku dan alat game milik Jounen-san, dan diketahui bahwa Takiyama-san dan Utsumi baru pertama kali bertemu. Hubungan mereka pun tidak akrab atau baru pertama kali bertemu (soto mono).

- Jarak psikologis

Jarak psikologis tercipta berdasarkan pada rasa hormat, dan kejauhan atau kedekatan. Apabila dilihat dari rasa hormat dari Takiyama-san kepada mitra tutur karena mitra tutur mengetahui bahwa Utsumi-san adalah seorang detektif. Apabila dilihat dari kejauhan antara Takiyama-san dengan mitra tutur, keberadaan antarpartisipan berada pada kelompok yang berbeda atau beda profesi dan hubungan antarpartisipan yang belum akrab.

Faktor penggunaan keigo tersebut dilatarbelakangi oleh beberapa hal yaitu faktor jarak sosial, jarak formalitas, dan jarak psikologis. Berdasarkan jarak sosial yang menjadi 
pertimbangannya adalah faktor hubungan sosial memiliki perbedaan profesi pekerjaan yaitu Takiyama-san sebagai pengacara, sedangkan Utsumi-san sebagai detektif. Jarak formalitas hubungan antarpartisipan adalah tidak saling kenal atau tidak ada hubungan keluarga maupun pekerjaan (soto no hito). Jarak psikologis Takiyama-san merendahkan diri sendiri terhadap mitra tutur, karena berbicara dengan seseorang yang belum akrab atau seseorang yang baru ditemui. Jadi dalam hal ini faktor dominan yang menjadi pertimbangan penggunaan keigo adalah jarak formalitas, karena penutur dan mitra tutur baru saja bertemu dan termasuk dalam kelompok soto mono. Karena orang Jepang menggunakan bahasa hormat keigo kepada orang yang baru ditemuinya.

\section{Simpulan}

Penggunaan keigo berdasarkan analisis data banyak ditemukan penggunaan bahasa hormat keigo (kenjougo dan teineigo) yang digunakan penutur kepada mitra tutur dalam lingkup uchi mono, situasi formal maupun tidak formal, memiliki kedudukan lebih tinggi dan usia yang lebih tua. Sedangkan penggunaan ragam bahasa keigo (sonkeigo) digunakan penutur kepada mitra tutur dalam lingkup soto mono, situasi formal maupun tidak formal, usia atau kedudukan yang lebih tinggi.

Posisi meue dalam lingkup uchimono, menempatkan posisi seseorang yang harus dihormati, sehingga meshita menggunakan bentuk ragam hormat (sonkeigo atau kenjougo) saat berbicara dengan meue. Posisi meshita dalam lingkup uchimono, menunjukkan hubungan yang dekat dan akrab, sehingga tidak masalah meue berbicara dengan menggunakan ragam sederhana (futsuu atau kenjougo). Kelompok sotomono merupakan orang dari kelompok luar dan memiliki hubungan yang tidak dekat, sehingga menggunakan ragam bahasa hormat (termasuk menggunakan sonkeigo). Ketika berbicara dengan mitra tutur dan mitra tutur tersebut dianggap sebagai anggota kelompoknya maka menggunakan ragam bahasa bentuk sederhana (futsuu atau teineigo). Tetapi sebaliknya, ketika berbicara dengan orang lain yang dianggap bukan anggota kelompoknya, maka menggunakan ragam bahasa sopan (sonkeigo atau kenjougo).

Berdasarkan analisis data faktor dominan yang menjadi pertimbangan penggunaan keigo dalam kelompok uchi mono adalah jarak sosial, karena penutur berbicara kepada mitra tutur 
lebih melihat berdasarkan posisi kedudukan atau usia. Sedangkan faktor dominan yang menjadi pertimbangan penggunaan keigo dalam kelompok soto mono adalah jarak sosial dan jarak formalitas, karena mitra tutur yang berbicara dengan Utsumi-san banyak yang tidak menggunakan ragam bahasa hormat (keigo), karena mitra tutur merasa usianya lebih tua dari Utsumi-san, dan menganggap tidak formal pembicaraannya karena bukan dari pekerjaannya.

\section{Referensi}

Abdul Chaer dan Leonie Agustiina (2010). Sosiolinguistik Perkenalan Awal. Jakarta : Rineka Cipta. Abdurrahman, A. (2011). Sosiolinguistik: Teori, Peran, Dan Fungsinya Terhadap Kajian Bahasa Sastra. LiNGUA: Jurnal Ilmu Bahasa dan Sastra, 3(1). https://doi.org/10.18860/ling.v3i1.571. [diakses pada 12 Maret 2020]

Astami, T. S. (2010). Pola Honorifik Undak-Usuk Keigo Bahasa Jepang yang Mencerminkan Nilai Uchi-Soto sebagai Wujud Identifikasi Kelompok. Humaniora, 1(1), 131-141. https://doi.org/10.2512/humaniora.v1i1.2156. [diakses pada 12 Maret 2020]

Elsa Angga Rini, E. (2017). Analisis Bahasa Hormat (Keigo) Dalam Film Nazotoki Wa Dinner No Atode 映画 [謎解きはディナーのあとで] における敬語 (Doctoral dissertation, Universitas Diponegoro). http://eprints.undip.ac.id/51751. [diakses pada 12 Maret 2020]

Ide, Sachiko. (1982). “Japanese Sociolinguistics: Politeness and Women's Language", dalam Lingua 57 (2-4). (357-385),. http://doi.org/10.1016/0024-3841(82)90009-2. [diakses pada tanggal 10 April 2020]

Muhammad, Mudlofar Imam (2017) Analisis Kesalahan Penggunaan Teineigo Studi Kasus Mahasiswa Sastra Jepang Tingkat 3 Angkatan 2012 Universitas Dian Nuswantoro. http://eprints.dinus.ac.id/id/eprint/22653. [diakses pada 10 April 2020]

Okamoto, Shigeko. "Situated Politeness: Manipulating Honorific and Non-Honorifics Expressions in Japanese Conversations" dalam Pragmatics 9:1, 51-74, International Pragmatics Association, 1999. https://doi.org/10.1075/prag.9.1.05oka. [diakses pada 27 Maret 2020]

Rachmadita, R., Fitriana, R., \& Karyati, A. (2020). Analisis Penggunaan Bahasa Sopan dalam Serial Animasi Hyouka. Ideal Sastra Jepang, 2(1). http://journal.unpak.ac.id/index.php.Idea/article/view/1829. [diakses pada 14 Maret 2020]

Saifudin, A. (2010). Analisis Pragmatik Variasi Kesantunan Tindak Tutur Terima Kasih Bahasa Jepang Dalam Film Beautiful Life Karya Kitagawa Eriko. LITE : Jurnal Bahasa, Sastra, dan Budaya 6 (2), 172-181. https://doi.org/10.33633/lite.v6i2.473. [diakses pada 27 Maret 2020].

Saifudin, A., Aryanto, B., Budi, IS. (2008). Analisis Fungsi Pragmatik Tindak Tutur Pertanyaan dalam Percakapan Bahasa Jepang antara Wisatawan Jepang dan Pemandu Wisata Indonesia di Candi Borobudur. LITE : Jurnal Bahasa, Sastra, dan Budaya 4 (1), 8-15.

Saifudin, A. (2005). Faktor Sosial Budaya dan Kesopanan Orang Jepang dalam Pengungkapan Orei no Kotoba. Laporan Penelitian Universitas Dian Nuswantoro. 
Saputro, W. A. (2019). Analisis Penggunaan Keigo dalam Variety show Dai Rokujyuu Nana-Kai NHK Kouhaku Uta Gassen Tahun 2016 (Doctoral dissertation, UNNES). http://lib.unnes.ac.id/34629. [diakses pada 11 April 2020]

Satyanto, S. (2018). Stategi Kesantunan Permintaan Bahasa Jepang dalam Drama "Engine", LITE : Jurnal Bahasa, Sastra, dan Budaya 14 (2), 154-165 https://doi.org/10.33633/lite.v14i2.2327. [diakses pada 12 April 2020]

Setiawan, A. (2019). Analisis Penggunaan Keigo dalam Drama Nihonjin No Shiranai Nihongo Karya Yoshihiro Izumi. http://repositori.usu.ac.id/handle/123456789/23665. [diakses pada 02 Mei 2020]

Yusuf, N., \& Rottie, D. C. (2019). Analisis Makna Sonkeigo Dan Kenjougo Dalam Buku Bahasa Jepang Bisnis. Jurnal Elektronik Fakultas Sastra Universitas Sam Ratulangi, 3. https://journal.unsrat.ac.i/index.php/jefs/article/view/25002. [diakses pada 20 April 2020] 